\title{
Erratum to: The accuracy of farmer-generated data in an agricultural citizen science methodology
}

\author{
Jonathan Steinke ${ }^{1,2}$ - Jacob van Etten ${ }^{1} \cdot$ Pablo Mejía Zelan ${ }^{3}$
}

Published online: 8 August 2017

(C) The Author(s) 2017

Erratum to: Agron. Sustain. Dev.

$$
\text { http://dx.doi.org/10.1007/s13593-017-0441-y }
$$

The acknowledgment text in the original research article should be replaced by the version below that includes the full USAID acknowledgment and an update to the first part (CGIAR acknowledgment).

This work was implemented as part of the CGIAR Research Program on Climate Change, Agriculture and Food Security (CCAFS), which is carried out with support from CGIAR Fund Donors and through bilateral funding agreements. For details please visit https://ccafs.cgiar.org/donors. The views expressed in this document cannot be taken to reflect the official opinions of these organizations. The project has been supported by USAID grant AID-OAA-F-14-00035 "Crowdsourcing crop improvement: Evidence base and outscaling model". The authors are very grateful to Dr. Juan Carlos Rosas and staff at Zamorano, as well as the field facilitators of the Honduran NGOs PRR and FIPAH for the support on site. We would like to thank Dr. Helen Ogden (Warwick) for an important pointer on statistics and Vincent Johnson for editing the manuscript. We thank five anonymous reviewers, whose contributions substantially improved the manuscript. Above all, we are grateful to the participating farmers for their commitment, time, and effort.

The online version of the original article can be found at http://dx.doi.org/ 10.1007/s13593-017-0441-y

Jonathan Steinke

j.steinke@cgiar.org Bioversity International, c/o CATIE, Turrialba 7170, Costa Rica

2 Division of Horticultural Economics, Humboldt-Universität zu Berlin, Unter den Linden 6, 10099 Berlin, Germany

3 Programa de Reconstrucción Rural, Horconcito, Santa Barbara, Honduras 